\title{
Insulin and Insulin-like Growth Factor-I Enhance Human Skeletal Muscle Protein Anabolism during Hyperaminoacidemia by Different Mechanisms
}

David A. Fryburg, Linda A. Jahn, Sherita A. Hill, Diana M. Oliveras, and Eugene J. Barrett

Division of Endocrinology and Metabolism, Department of Internal Medicine, and the General Clinical Research Center, the University of Virginia Health Sciences Center, Charlottesville, VA 22908

\section{Abstract}

Insulin inhibits proteolysis in human muscle thereby increasing protein anabolism. In contrast, IGF-I promotes muscle protein anabolism principally by stimulating protein synthesis. As increases or decreases of plasma amino acids may affect protein turnover in muscle and also alter the muscle's response to insulin and/or IGF-I, this study was designed to examine the effects of insulin and IGF-I on human muscle protein turnover during hyperaminoacidemia. We measured phenylalanine balance and $\left[{ }^{3} \mathrm{H}\right]$ phenylalanine kinetics in both forearms of 22 postabsorptive adults during a continuous $\left[{ }^{3} \mathrm{H}\right]$ phenylalanine infusion. Measurements were made basally and at 3 and $6 \mathrm{~h}$ after beginning a systemic infusion of a balanced amino acid mixture that raised arterial phenylalanine concentration about twofold. Throughout the $6 \mathrm{~h}, 10$ subjects received insulin locally $(0.035 \mathrm{mU} / \mathrm{min}$ per $\mathrm{kg})$ into one brachial artery while 12 other subjects were given intraaterial IGF-I $(100 \mathrm{ng} / \mathrm{min}$ per $\mathrm{kg}$ ) to raise insulin or IGF-I concentrations, respectively, in the infused arm. The contralateral arm in each study served as a simultaneous control for the effects of amino acids (aa) alone.

Glucose uptake and lactate release increased in the insulin- and IGF-I-infused forearms $(P<0.01)$ but did not change in the contralateral (aa alone) forearm in either study. In the aa alone arm in both studies, hyperaminoacidemia reversed the postabsorptive net phenylalanine release by muscle to a net uptake $(P<0.025$, for each $)$ due to a stimulation of muscle protein synthesis. In the hormoneinfused arms, the addition of either insulin or IGF-I promoted greater positive shifts in phenylalanine balance than the aa alone arm $(P<0.01)$. With insulin, the enhanced anabolism was due to inhibition of protein degradation $(P$ $<0.02)$, whereas IGF-I augmented anabolism by a further stimulation of protein synthesis above aa alone $(P<0.02)$. We conclude that: $(a)$ hyperaminoacidemia specifically stimulates muscle protein synthesis; $(b)$ insulin, even with hyperaminoacidemia, improves muscle protein balance solely by inhibiting proteolysis; and (c) hyperaminoacidemia combined with IGF-I enhances protein synthesis more

Address correspondence to David A. Fryburg, University of Virginia Health Science Center, Box 5116, MR4, Charlottesville, VA. Phone: 804-924-1175; FAX: 804-924-1284.

Received for publication 28 March 1995 and accepted in revised form 30 June 1995.

J. Clin. Invest.

(C) The American Society for Clinical Investigation, Inc.

0021-9738/95/10/1722/08 \$2.00

Volume 96, October 1995, 1722-1729 than either alone. (J. Clin. Invest. 1995.96:1722-1729.) Key words: phenylalanine - proteolysis - protein synthesis • blood flow • forearm

\section{Introduction}

Insulin or IGF-I, when infused under euglycemic conditions, lowers the circulating concentration of most amino acids (1, 2 ). Kinetic studies of whole body amino acid flux suggest that inhibition of protein degradation is responsible for the decline of plasma amino acid concentrations (3-7). Nonoxidative amino acid disposal, an index of protein synthesis in the whole body, is either unchanged or declines with euglycemic insulin or IGF-I infusions associated with hypoaminoacidemia. If euaminoacidemia is maintained during euglycemic hyperinsulinemia, then insulin's ability to suppress whole body protein degradation is enhanced over the response without amino acid replacement $(8,9)$. Thus, ambient amino acid concentrations modulate the whole body protein metabolic response to insulin. Despite enhancing insulin's effect on protein degradation, however, no action of insulin to stimulate whole body protein synthesis was observed in these studies.

Analogous to the whole body response, in human skeletal muscle euglycemic hyperinsulinemia improves muscle protein balance. Most (10-13) but not all human studies (14) attribute insulin's anabolic action to an inhibition of protein degradation. Likewise in animals, insulin does not enhance muscle protein synthesis $(15-18)$. The lack of an in vivo effect of insulin on muscle protein synthesis has been puzzling inasmuch as numerous in vitro studies have documented that insulin can stimulate protein synthesis in skeletal and cardiac muscle as well as in nonmuscle tissues (19-21).

In contrast to insulin, IGF-I increases muscle protein synthesis both in vitro $(21,24)$ as well as in vivo in both humans (25) and animals $(26,27)$. When infused directly into the human forearm, IGF-I stimulates muscle protein synthesis

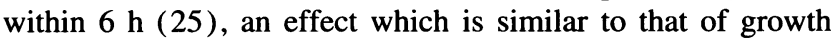
hormone $(\mathrm{GH})^{1}$ in the same system (28). At higher doses IGF-I promoted additional protein anabolism by inhibiting proteolysis without further stimulating protein synthesis (25). Thus, although both insulin and IGF-I can suppress muscle proteolysis, they are clearly distinguished by the ability of IGF-I to increase protein synthesis in forearm muscle in the postabsorptive state.

As insulin decreases plasma and intracellular amino acid concentrations, it has been suggested that amino acids must be supplied during an infusion of insulin to elicit an effect of insulin on bulk protein synthesis (29). As amino acids may independently affect whole body and muscle protein metabo-

1. Abbreviations used in this paper: aa, amino acid; GH, growth hormone; INS, insulin; PHE, phenylalanine; tRNA, transfer RNA. 


\section{EXPERIMENTAL PROTOCOL}

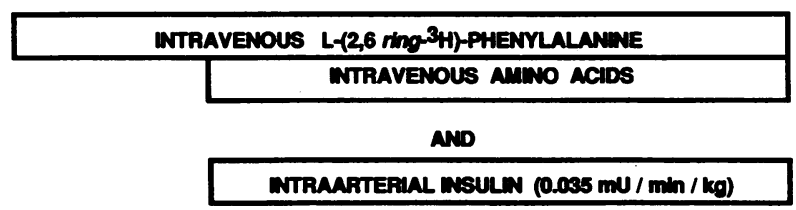

OR

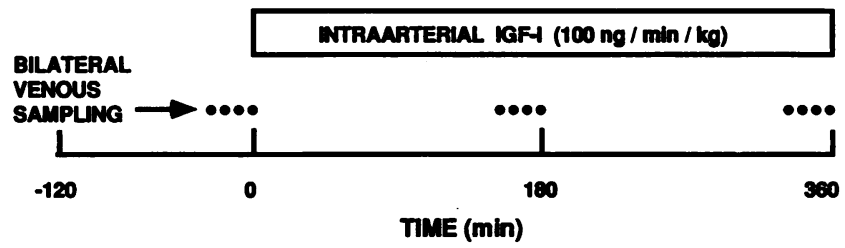

Figure 1. Experimental paradigm for INS + aa and IGF+aa studies. See text for details.

lism $(9,30-35)$, discriminating the effects of the infused amino acids from those of added insulin or other anabolic agents has been difficult. Investigators have addressed this by either titrating the amino acid replacement to maintain postabsorptive plasma concentrations of at least an index amino acid or by raising the plasma amino acid concentrations in the presence or absence of infused insulin $(8,13,29,32)$. With either approach it has not been possible to match plasma concentrations of most amino acids, and therefore the independent effects of insulin and amino acids on muscle protein synthesis remain unresolved.

The primary goal of this study was to determine if the provision of amino acids to postprandial levels would qualitatively or quantitatively alter muscle tissue's response to insulin or IGF-I. By using bilateral forearm cannulations, forearm muscle of both arms were exposed to identical amino acid concentrations, but insulin or IGF-I was infused in only one arm. With this design, the present study avoided the complex task of matching systemic amino acids during separate or sequential infusion studies. In the setting of identical hyperaminoacidemia in both forearms, therefore, the effects of locally infused insulin or IGF-I on forearm muscle were compared to those of amino acids alone (no hormone). This design also afforded examination of the effects of amino acids, per se, on human muscle protein metabolism.

\section{Methods}

Subjects. 22 healthy, normal weight, adult, volunteers, ages $20-32 \mathrm{yr}$ were admitted to the University of Virginia General Clinical Research Center the evening before the study. No subject was taking any medication and all female participants had a negative serum pregnancy test one to $2 \mathrm{~d}$ before the study. The study protocol was approved by the University of Virginia Human Investigation Committee and each subject gave written consent.

Experimental protocol. Fig. 1 schematically depicts the experimental protocol. After an overnight 12-h fast, a brachial artery and an ipsilateral, retrograde, median cubital (deep) vein catheter were placed percutaneously. In the contralateral arm, a second, retrograde, median cubital vein catheter was placed. Each subject received a primed $(\sim 33 \mu \mathrm{Ci})$, continuous $(0.43 \mu \mathrm{Ci} / \mathrm{min})$ infusion of $\mathrm{L}-\left[\right.$ ring $\left.2,6{ }^{3} \mathrm{H}\right]$ phenylalanine through a catheter placed in the lower extremity. After a 90-min tracer equilibration period, quadruplicate, paired arterial and bilateral venous samples were taken for phenylalanine concentration and specific activity, and glucose, lactate, and insulin concentrations from the arterial and each forearm venous catheter. Forearm blood flow was measured in each arm after each set of arterial and venous samples by capacitance plethysmography.

After obtaining baseline samples, a balanced amino acid mixture (Travesol 10\%; Clintec Nutrition, Deerfield, IL) was infused into a vein in the lower extremity at a rate of $0.015 \mathrm{ml} / \mathrm{min}$ per $\mathrm{kg}$ for $6 \mathrm{~h}$. In the arm containing the arterial catheter, either insulin $(0.035 \mathrm{mU} / \mathrm{min}$ per $\mathrm{kg}$ body weight, $n=10$, designated insulin + amino acid (INS $+\mathrm{aa}$ ) study) or IGF-I ( $100 \mathrm{ng} / \mathrm{min}$ per $\mathrm{kg}, \boldsymbol{n}=12$, designated IGF+aa study) was continuously infused intraarterially (IGF-I was provided by Genentech, Inc., South San Francisco, CA). Quadruplicate blood samples were again taken from each of the three sampling catheters between 150 $180 \mathrm{~min}$ and between $300-360 \mathrm{~min}$ of the amino acid infusion. Bilateral forearm blood flow was measured in quadruplicate during each sampling period.

Analytic methods. Whole blood glucose and lactate concentrations were measured by a combined glucose/lactate analyzer (Yellow Springs Instruments, Yellow Springs, OH). Plasma insulin and IGF-I (after acid ethanol extraction) were measured by radioimmunoassay. Phenylalanine concentration and specific activity were measured as previously described (28).

Calculations of forearm phenylalanine kinetics. The net forearm balance for amino acids was calculated from the Fick principle:

Net balance $=([\mathrm{A}]-[\mathrm{V}] \times \mathrm{F}$

where $[\mathrm{A}]$ and $[\mathrm{V}]$ are arterial and venous substrate concentrations and $\mathrm{F}$ is forearm blood flow in $\mathrm{ml} / \mathrm{min}$ per $100-\mathrm{ml}$ forearm volume. Measurement of the absolute rates of synthesis and breakdown of muscle protein requires knowing the phenylalanine specific activity in the phenylalanyl-transfer RNA (tRNA) pool being used for protein synthesis. This is not experimentally accessible in the forearm. The rates of protein synthesis and degradation can be estimated from the kinetics of exchange of labeled phenylalanine across the forearm as previously described $(38,36,3739)$. Equations have been presented for estimating forearm protein synthesis and degradation that were based upon the use of either arterial or deep venous specific activity of $\left[{ }^{3} \mathrm{H}\right]$ phenylalanine to approximate phenylalanyl-tRNA specific activity $(10,36,37)$. Inasmuch as recent data suggest that the specific activity of phenylalanine or leucine in venous plasma more closely approximates that of the tRNA pool $(17,38)$, we have used venous specific activity to estimate rates of protein synthesis and degradation. Qualitatively comparable results were obtained using the arterial phenylalanine specific activity as the precursor pool (see below). Using the venous phenylalanine specific activity to reflect the precursor pool for protein synthesis, synthesis (S) is given by:

$\mathrm{S}=\left(\left[\mathrm{DPM}_{\mathrm{art}}-\mathrm{DPM}_{\mathrm{vein}}\right] \times\right.$ Flow $) / \mathrm{SA}_{\text {vein }}$

and muscle protein breakdown (B) as:

$\mathrm{B}=\mathrm{S}-$ Net balance

As described previously $(10,36)$ we also estimated the rate of tissue disposal of phenylalanine $\left(R_{\mathrm{d}}\right)$ using arterial specific activity as an estimate of the precursor pool and the rate of tissue release of substrate into the draining venous system $\left(R_{\mathrm{a}}\right)$. That is,

Net Balance $=R_{\mathrm{d}}-\boldsymbol{R}_{\mathrm{a}}$

Since phenylalanine is not synthesized, catabolized, or concentrated in muscle, the amount of phenylalanine extracted from arterial plasma $\left(R_{\mathrm{d}}\right)$ should, like $S$ at steady state, reflect utilization of phenylalanine for muscle protein synthesis. $R_{\mathrm{d}}$ is given by the equation,

$R_{\mathrm{d}}=\left(\left[\mathrm{dpm}_{\mathrm{arr}}-\mathrm{dpm}_{\text {vein }}\right] \times\right.$ Flow $) / \mathrm{SA}_{\mathrm{art}}$

The $R_{\mathrm{a}}$, like $\mathrm{B}$, is a measure of tissue protein breakdown and is obtained from Eq. 4. 
Table I. Glucose, Lactate, Phenylalanine, Insulin, and IGF-I Concentrations

\begin{tabular}{lcccc}
\hline & Basal & $3 \mathrm{~h}$ & $6 \mathrm{~h}$ & $P$ \\
\hline Insulin + amino acid infusion & & & & \\
$\quad$ Glucose artery (mM) & $5.2 \pm 0.2$ & $5.1 \pm 0.2$ & $5.0 \pm 0.0$ & $\mathrm{NS}$ \\
Lactate artery (mM) & $0.60 \pm 0.06$ & $0.63 \pm 0.05$ & $0.5 \pm 0.04$ & $\mathrm{NS}$ \\
Insulin vein (pmol/liter) & $30 \pm 6$ & $606 \pm 36^{*}$ & $444 \pm 42^{*}$ & $<0.001$ \\
Insulin contralateral vein & & & & \\
$\quad$ (pmol/liter) & $24 \pm 6$ & $48 \pm 6$ & $54 \pm 12$ & $\mathrm{NS}$ \\
Growth hormone (ng/ml) & $5.0 \pm 2.2$ & $1.3 \pm 0.5$ & $2.9 \pm 1.1$ & $\mathrm{NS}$ \\
IGF-I + amino acid infusion & & & & \\
Glucose artery (mM) & $5.5 \pm 0.2$ & $5.2 \pm 0.2$ & $4.9 \pm 0.2^{\ddagger}$ & $<0.01$ \\
Lactate artery (mM) & $0.50 \pm 0.03$ & $0.62 \pm 0.04^{\ddagger}$ & $0.58 \pm 0.02^{\ddagger}$ & $<0.01$ \\
Insulin vein (pmol/liter) & $36 \pm 6$ & $30 \pm 6$ & $24 \pm 6^{\ddagger}$ & $<0.05$ \\
IGF-I vein (ng/ml) & $283 \pm 38$ & $763 \pm 83^{*}$ & $815 \pm 71^{*}$ & $<0.001$ \\
IGF-I contralateral vein & & & & \\
$\quad$ (ng/ml) & $259 \pm 39$ & $420 \pm 61^{*}$ & $577 \pm 63^{\S}$ & $<0.005$ \\
Growth hormone (ng/ml) & $1.7 \pm 0.5$ & $2.9 \pm 0.8$ & $0.9 \pm 0.3^{\S}$ & $<0.02$ \\
& & & &
\end{tabular}

Data expressed as mean \pm SEM. $P$ indicates ANOVA by repeated measures within arm. Post hoc testing by Duncan's test: ${ }^{*} P<0.01$ vs basal; ${ }^{\ddagger} P<0.05$ vs basal; ${ }^{8} P<0.05$ vs $3 \mathrm{~h}$.

Whole body phenylalanine flux. Whole body phenylalanine flux or $R_{\mathrm{a}}$ was calculated using the equation:

$R_{\mathrm{a}}=\mathrm{IR} / \mathrm{SA}_{\mathrm{a}}$

in which IR is the infusion rate of $\left[{ }^{3} \mathrm{H}\right]$ phenylalanine and $\mathrm{SA}_{\mathrm{a}}$ the specific activity of $\left[{ }^{3} \mathrm{H}\right]$ phenylalanine in arterial plasma. For the amino acid infusion periods, endogenous phenylalanine flux was calculated from the difference between total phenylalanine flux and the exogenous phenylalanine infusion rate.

Data presentation and statistical analysis. All data are presented as mean \pm SEM. Data on hormone concentrations, bilateral forearm substrate balance, and whole body and bilateral forearm amino acid kinetics are presented for each of the sample periods, i.e., basal, 3 and $6 \mathrm{~h}$. For comparison between forearms within the INS \pm aa, the study arm not receiving the brachial artery insulin infusion is designated as aa. Similarly, in the IGF+aa study, the arm contralateral to the IGF-I infusion is also designated aa. Two of the INF+aa and three of the IGF+aa studies did not have aa alone arms. When paired comparisons between the two arms (INS + aa vs aa or IGF+aa vs aa) were undertaken, those subjects without the aa control arm were not included in the analysis. Stochastic comparisons were made using analysis of variance with repeated measures and post hoc, two-tailed comparisons with Duncan's test (True Epistat; Epistat Services, Richardson, TX).

\section{Results}

Forearm glucose, lactate, insulin, GH, and IGF-I concentrations; phenylalanine concentrations and specific activities. The arterial concentration of glucose was unchanged during the systemic amino acid infusion in either study group (Table I). The arterial lactate concentration likewise remained stable at basal during the $6 \mathrm{~h}$ of insulin or IGF-I infusion. During the basal period the venous plasma insulin concentration averaged around $30 \mathrm{pmol} /$ liter in both study groups (Table I). In the INS + aa study insulin concentrations rose markedly to $\sim 600 \mathrm{pmol} /$ liter in the insulin-infused arm and remained elevated for $6 \mathrm{~h}$. Insulin concentrations rose modestly but not significantly in the contralateral arm in these subjects. In the IGF+aa study insulin fell slightly but significantly (Table I). GH concentrations were unchanged in the INS + aa study but declined significantly in the IGF+aa study. The concentrations of IGF-I rose in the deep forearm vein draining both the IGF-I infused arm and the contralateral arm. In both study groups the amino acid infusion raised the systemic concentration of phenylalanine $\sim$ twofold (Table II). Table II summarizes the changes in phenylalanine concentrations and specific activities for both the INS + aa and IGF+aa studies.

Forearm glucose and lactate balances and blood flows. Glucose uptake by the aa alone forearm did not change during either the INS + aa and the IGF + aa studies (Table III). In contrast, in both the INS + aa or IGF+aa forearms net forearm glucose uptake rose five- to sevenfold in response to the infusions at both at 3 and $6 \mathrm{~h}$ (Table III). Similarly, forearm lactate release in the aa alone arms was unchanged, but increased in the insulin and in the IGF-I infused forearms. Blood flow increased significantly in both the hormone-infused arm and in the contralateral arm in both study groups (Table III). The most marked increases in flow, greater than threefold above basal, were provoked by the IGF-I infusion as previously reported during euaminoacidemia (25).

Whole body phenylalanine fluxes. In the INS+aa study, whole body phenylalanine flux rose during the systemic amino acid infusion $(0.44 \pm 0.03$ to $0.78 \pm 0.05 \mu \mathrm{mol} / \mathrm{min}$ per $\mathrm{kg}$ at 6 $\mathrm{h}(P<0.01)$. Endogenous phenylalanine flux (total phenylalanine flux - rate of phenylalanine infusion) declined to $0.31 \pm 0.05$ and $0.29 \pm 0.05$ at 3 and $6 \mathrm{~h}$, respectively, $(P<0.01)$ with amino acid infusion. Similar observations were made in the IGF+aa study, in which whole body phenylalanine flux rose $(0.35 \pm 0.03$ to $0.64 \pm 0.05$ basal vs $6 \mathrm{~h}, P<0.01)$, while

Table II. Phenylalanine Concentrations and Specific Activities in the Insulin and IGF.I Studies

\begin{tabular}{|c|c|c|c|c|c|c|c|c|}
\hline & \multicolumn{4}{|c|}{ Insulin + amino acids } & \multicolumn{4}{|c|}{ IGF + amino acids } \\
\hline & BAS & $3 \mathrm{~h}$ & $6 \mathrm{~h}$ & $P$ & BAS & $3 \mathrm{~h}$ & $6 \mathrm{~h}$ & $P$ \\
\hline PHE Art & $49 \pm 1$ & $103 \pm 6$ & $113 \pm 4 *$ & $<0.0005$ & $44 \pm 2$ & $94 \pm 3 *$ & $99 \pm 3 *$ & $<0.001$ \\
\hline PHE Vein & $56 \pm 1$ & $95 \pm 6^{*}$ & $107 \pm 5^{*}$ & $<0.001$ & $50 \pm 2$ & $87 \pm 3$ & $93 \pm 4$ & $<0.001$ \\
\hline PHE CL Vein & $56 \pm 2$ & $94 \pm 6^{*}$ & $108 \pm 4 *$ & $<0.001$ & $49 \pm 2$ & $88 \pm 2$ & $97 \pm 3$ & $<0.001$ \\
\hline PHE SA $_{a}$ & $20 \pm 1$ & $12 \pm 1 *$ & $11 \pm 1^{*}$ & $<0.001$ & $22 \pm 1$ & $13 \pm 1 *$ & $12 \pm 1^{*}$ & $<0.001$ \\
\hline PHE SA $_{v}$ & $13 \pm 1$ & $11 \pm 1^{*}$ & $11 \pm 1 *$ & $<0.01$ & $16 \pm 1$ & $12 \pm 1 *$ & $12 \pm 1^{*}$ & $<0.001$ \\
\hline PHE $S A C L_{v}$ & $13 \pm 1$ & $10 \pm 1 *$ & $10 \pm 1 *$ & $<0.01$ & $16 \pm 1$ & $11 \pm 1^{*}$ & $11 \pm 1^{*}$ & $<0.01$ \\
\hline
\end{tabular}

Data expressed as mean \pm sem. Phenylalanine concentrations in $\mu$ mol/liter. Phenylalanine specific activities $(S A)$ in dpm/nmol to nearest integer). CL, contralateral. $P$ indicates ANOVA by repeated measures within arm. Post hoc testing by Duncan's test: $* P<0.01$ vs basal. 
Table III. Responses of Forearm Blood Flow and Glucose and Lactate Balances to Amino Acids Alone or in Combination with Insulin or IGF-I

\begin{tabular}{|c|c|c|c|c|c|c|c|c|}
\hline & BAS & $3 \mathrm{~h}$ & $6 \mathrm{~h}$ & $P$ & BAS & $3 \mathrm{~h}$ & $6 \mathrm{~h}$ & $P$ \\
\hline & \multicolumn{4}{|c|}{ Insulin + amino acids } & \multicolumn{4}{|c|}{ Amino acids } \\
\hline Blood flow & $2.9 \pm 0.3$ & $3.7 \pm 0.4$ & $5.1 \pm 0.7 *$ & $<0.0005$ & $2.9 \pm 0.3$ & $3.0 \pm 0.3^{\ddagger}$ & $4.3 \pm 0.5^{\ddagger}$ & $<0.02$ \\
\hline Glucose balance & $0.4 \pm 0.1$ & $2.6 \pm 0.5^{*}$ & $1.9 \pm 0.5^{*}$ & $<0.001$ & $0.6 \pm 0.2$ & $0.8 \pm 0.2$ & $0.5 \pm 0.1$ & NS \\
\hline \multirow[t]{2}{*}{ Lactate balance } & $-0.2 \pm 0.1$ & $-0.7 \pm 0.1^{\ddagger}$ & $-0.6 \pm 0.1^{\ddagger}$ & $<0.01$ & $-0.1 \pm 0.1$ & $-0.1 \pm 0.1$ & $-0.1 \pm 0.1$ & NS \\
\hline & \multicolumn{4}{|c|}{$I G F-I+$ amino acids } & \multicolumn{4}{|c|}{ Amino acids } \\
\hline Blood flow & $3.2 \pm 0.3$ & $6.4 \pm 0.9 *$ & $11.4 \pm 2.1^{* 8}$ & $<0.0005$ & $2.4 \pm 0.3$ & $2.8 \pm 0.5^{\ddagger}$ & $3.8 \pm 0.5^{\ddagger}$ & $=0.005$ \\
\hline Glucose balance & $0.5 \pm 0.2$ & $2.5 \pm 0.5^{*}$ & $2.4 \pm 0.6^{*}$ & $<0.005$ & $0.6 \pm 0.1$ & $0.6 \pm 0.1$ & $0.6 \pm 0.2$ & NS \\
\hline Lactate balance & $-0.4 \pm 0.1$ & $-0.7 \pm 0.1^{*}$ & $-1.1 \pm 0.1^{*}$ & $<0.001$ & $-0.2 \pm 0.2$ & $-0.1 \pm 0.3$ & $0.0 \pm 0.3$ & NS \\
\hline
\end{tabular}

Data expressed as mean \pm SEM. Blood flow in units of $\mathrm{ml} / \mathrm{min}$ per $100 \mathrm{ml}$ forearm volume. Glucose and lactate balances in $\mu \mathrm{mol} / \mathrm{min}$ per $100 \mathrm{ml}$. $P$ indicates ANOVA by repeated measures within arm. Post hoc testing by Duncan's test: ${ }^{*} P<0.01$ vs basal; ${ }^{\ddagger} P<0.05$ vs basal; ${ }^{8} P<0.05$ vs $3 \mathrm{~h}$; BAS, basal.

endogenous whole body phenylalanine flux fell to $0.15 \pm 0.05$ $(P<0.01)$.

Forearm phenylalanine kinetics. Table IV summarizes the mean, absolute responses in each of the four experimental arms. To emphasize the comparisons among the effects of aa alone and INS + aa or IGF+aa, Fig. 2 depicts the mean changes between the basal and 6-h time point for each of these four study arms.

INS +aa. As shown in Table IV, in the basal period there were comparable, net releases of phenylalanine by both forearms within each study group. In the INS + aa study, phenylalanine balance across both the insulin infused and the aa alone arm switched from a net release to a net uptake (Table IV, both $P<0.001)$. In the aa alone arm, the shift in phenylalanine (PHE) balance was due to an increase of $20 \mathrm{nmol} / \mathrm{min}$ per 100 $\mathrm{ml}$ in PHE $\mathrm{S}$ (an index of protein synthesis). Although PHE $B$, an index of muscle protein degradation, appeared to decline transiently (at $3 \mathrm{~h}$ ) with hyperaminoacidemia, this change did not reach statistical significance (Table IV).

In comparison to the aa alone arm, the balance of phenylalanine at $6 \mathrm{~h}$ was significantly more positive in the insulin-infused forearm $(26 \pm 4$ v $6 \pm 4 \mathrm{nmol} / \mathrm{min}$ per $100 \mathrm{ml}, P<0.001)$. In the insulin-infused, like the aa arm, the shift in phenylalanine balance was maintained throughout the $6 \mathrm{~h}$ of study (Table IV). The tracer kinetic measurements indicated that compared to basal, PHE S was comparably enhanced in both arms at 3 and $6 \mathrm{~h}$. There was no significant difference in the rate of muscle protein synthesis between the arm exposed to hyperaminoacidemia alone and that exposed to high insulin concentrations as well $(70 \pm 7$ and $68 \pm 5 \mathrm{nmol} / \mathrm{min}$ per $100 \mathrm{ml})$. However, there was a significant, sustained decline in protein degradation in the insulin-infused arm that was not seen in the contralateral arm (Table IV and Fig. 2). This appeared to account for the improved net phenylalanine balance seen in the insulin infused compared to the contralateral arm.

$I G F+a a$. In the IGF+aa study, the aa alone arm responded quite similarly to the aa alone forearm in the INS+aa study (Table IV). aa alone prompted a significant improvement in forearm PHE balance due to a rise in PHE S (by $44 \%$, basal vs $6 \mathrm{~h}, P<0.02)$. Like the aa alone arm, in the IGF+aa arm PHE balance shifted from net catabolism to anabolism. As observed with insulin, IGF-I's effect on PHE balance was additive with aa, yielding a much more marked change in PHE balance ( $78 \pm 12$ vs $19 \pm 6 \mathrm{nmol} / \mathrm{min}$ per $100 \mathrm{ml}, \mathrm{IGF}+$ aa vs aa

Table IV. Responses of Forearm Phenylalanine Balance and Protein Synthesis and Degradation to Amino Acids Alone or in Combination with Insulin or IGF-I

\begin{tabular}{|c|c|c|c|c|c|c|c|c|}
\hline & BAS & $3 \mathrm{~h}$ & $6 \mathrm{~h}$ & $P$ & BAS & $3 \mathrm{~h}$ & $6 \mathrm{~h}$ & $P$ \\
\hline & \multicolumn{4}{|c|}{ Insulin + amino acids } & \multicolumn{4}{|c|}{ Amino acids } \\
\hline Balance & $-21 \pm 2$ & $31 \pm 5 *$ & $26 \pm 4^{*}$ & $<0.0001$ & $-19 \pm 4$ & $16 \pm 6^{*}$ & $6 \pm 4 *$ & $<0.0001$ \\
\hline Synthesis & $46 \pm 6$ & $78 \pm 8^{\ddagger}$ & $68 \pm 5^{\ddagger}$ & $<0.02$ & $50 \pm 8$ & $67 \pm 9$ & $70 \pm 7$ & $=0.09$ \\
\hline \multirow[t]{2}{*}{ Breakdown } & $67 \pm 11$ & $47 \pm 5^{*}$ & $42 \pm 5^{*}$ & $<0.01$ & $69 \pm 11$ & $51 \pm 6$ & $64 \pm 7$ & NS \\
\hline & \multicolumn{4}{|c|}{$I G F-I+$ amino acids } & \multicolumn{4}{|c|}{ Amino acids } \\
\hline Balance & $-17 \pm 2$ & $36 \pm 11^{*}$ & $61 \pm 18^{5}$ & $<0.002$ & $-14 \pm 2$ & $5 \pm 6^{\ddagger}$ & $5 \pm 6^{\ddagger}$ & $=0.025$ \\
\hline Synthesis & $36 \pm 3$ & $82 \pm 9 *$ & $101 \pm 19^{*}$ & $<0.005$ & $32 \pm 5$ & $55 \pm 7^{\ddagger}$ & $46 \pm 5^{\ddagger}$ & $<0.02$ \\
\hline Breakdown & $54 \pm 4$ & $45 \pm 13$ & $40 \pm 13$ & NS & $46 \pm 8$ & $50 \pm 9$ & $41 \pm 5$ & NS \\
\hline
\end{tabular}

Data expressed as mean \pm sem in nmols phenylalanine/min per $100 \mathrm{ml} . P$ indicates ANOVA by repeated measures within arm. Post hoc testing by Duncan’s test: ${ }^{*} P<0.01$ vs basal; ${ }^{\ddagger} P<0.05$ vs basal; ${ }^{8} P<0.05$ vs $3 \mathrm{~h}$; BAS, basal. 

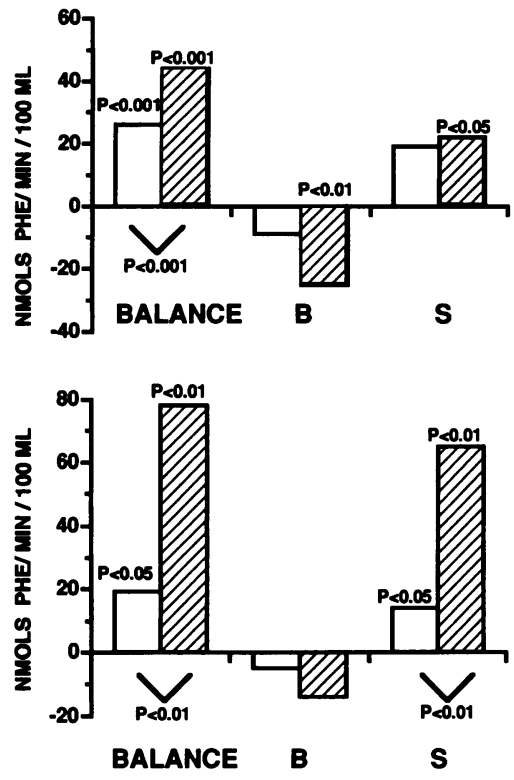

Figure 2. Comparisons of the changes in phenylalanine balance, breakdown $(B)$, and synthesis $(S)$ due to amino acids alone (aa, open bars) or insulin plus amino acids (INS+aa, hatched bars) in the top panel and aa (open bars) versus IGF plus amino acids (IGF+aa, hatched bars) in the lower panel. Significant changes in individual variables are indicated by significance level on top of the bar. Comparisons between aa and INS + aa or IGF+aa are indicated below a pair of bars.

alone, $P<0.01$, Fig. 2). The tracer measurements indicated that this was entirely attributable to an approximate tripling of PHE $S$ over basal $(P<0.005)$, an effect on PHE S greater than aa alone $(P<0.01$, Table IV, Fig. 2$)$.

When contrasted with the effect of INS + aa, the improvement in PHE balance was significantly greater with IGF+aa arm (Fig. 2, $P<0.01$ ), despite comparable actions on forearm glucose uptake and lactate release. Inasmuch as IGF-I did not affect protein degradation but did stimulate protein synthesis, the more marked effect of IGF-I on protein balance could only be attributed to its effect on protein synthesis. Indeed, the mean change in PHE S was significantly greater in the IGF+aa group compared with the INS + aa group ( $65 \pm 18$ vs $22 \pm 4$, IGF+aa vs INS+aa, $P<0.05$; Fig. 2 ).

From the above results it can be concluded that hyperaminoacidemia alone significantly affects forearm protein turnover, as do the combined INS + aa and IGF+aa infusions. The specific effects of each hormone in the setting of hyperaminoacidemia can be further discerned by subtracting the effects observed in the aa alone arm from the paired INS + aa or IGF+aa arms. During the basal period the values for the difference in PHE balance, $S$, and B between paired arms were not different than zero in each of the study groups (i.e., the arms were equivalent; Table IV). However, after subtracting the effect of hyperaminoacidemia in the contralateral arm from the combined effect of hormone + aa in the hormone infused arm, IGF-I had a greater effect than insulin on the changes in both PHE balance $(P<0.01)$ and PHE S $(P<0.08)$. In contrast, insulin specifically inhibited proteolysis, while IGF-I did not.

The kinetics of forearm protein turnover were also analyzed considering arterial phenylalanine to index the pool being used for tracing protein turnover (see Methods). In general, use of the arterial phenylalanine specific activity as the precursor pool for estimating muscle protein synthesis and degradation yielded results comparable to those presented above based on use of the venous precursor pool. Specifically, PHE $R_{\mathrm{d}}$ (like $\mathrm{S}$, an index for protein synthesis) increased in the aa alone arm in both study groups $(P<0.01$, for each $)$ with no significant change in PHE $R_{\mathrm{a}}$ (like $\mathrm{B}$, an index of proteolysis). In the
INS + aa arm, PHE $R_{\mathrm{d}}$ increased $(P<0.01)$ and PHE $R_{\mathrm{a}}$ declined $(P<0.03)$. In the IGF + aa arm, there was a marked increased in $R_{\mathrm{d}}(P<0.01)$ but no significant change in $R_{\mathrm{a}}$. Thus, for both hormone infused forearms, the findings are comparable irrespective of the precursor pool model used for tracing protein turnover.

\section{Discussion}

Two issues are addressed with this study design which bear discussion. The first is the specific effect of hyperaminoacidemia on muscle protein turnover and the second the interaction between insulin or IGF-I with hyperaminoacidemia in regulating skeletal muscle protein turnover.

In both study groups, hyperaminoacidemia shifted PHE balance from a net release to a net uptake in the aa alone forearm during the first $3 \mathrm{~h}$ which persisted at $6 \mathrm{~h}$. As phenylalanine is transported into muscle by the L-system, but is not accumulated against a concentration gradient (39), the raised arterial phenylalanine concentration would be expected to augment phenylalanine entry into tissue as the phenylalanine concentration in the interstitial and intracellular water rises. Considering this and the observed rise in arterial phenylalanine between the basal period and $3 \mathrm{~h}(\sim 52 \mu \mathrm{mol} / \mathrm{liter})$, simple partitioning of phenylalanine into the cell and interstitial water $(60 \mathrm{ml} / 100 \mathrm{ml}$ of forearm) could account for the net disposal of $\sim 3,000 \mathrm{nmol}$ of phenylalanine $/ 100 \mathrm{ml}$ forearm. In the aa alone arm, the change in net balance seen at $3 \mathrm{~h}$ of amino acid infusion $(-19$ to +16 and -14 to $+5 \mathrm{nmol} / \mathrm{min}$ per $100 \mathrm{ml}$, for the insulin and IGF-I studies, respectively) would, if present throughout the 3-h period, result in a net delivery of $\sim 3,200-6,300 \mathrm{nmol}$ phenylalanine $/ 100 \mathrm{ml}$ forearm. Thus, much of the observed shift in phenylalanine balance seen during the first $3 \mathrm{~h}$ could be simply due to raising tissue phenylalanine concentration in pace with its rise in plasma, without needing to invoke changes in tissue protein metabolism as suggested by others (35) based on brief $(3 \mathrm{~h})$ amino acid infusions.

Between 3 and $6 \mathrm{~h}$ of amino acid infusion, arterial phenylalanine concentration rose very little ( $\sim 10 \mu \mathrm{mol} /$ liter $)$. During this period the persistently positive phenylalanine balance cannot be attributable to simply raising the cell and interstitial water phenylalanine concentration and suggests a true anabolic shift in phenylalanine balance. Beyond filling the intracellular space, the further increment in forearm phenylalanine balance could result either from a suppression of protein degradation, a stimulation of protein synthesis or a combination of these processes. The measurements of tritiated phenylalanine kinetics across the forearm distinguish these mechanisms. We focused particularly on measurements obtained during the basal period and at $6 \mathrm{~h}$. The latter should reflect more closely a steady state measurement given the minimal change in phenylalanine concentration and specific activity between 3 and $6 \mathrm{~h}$. In the aa arm, at $6 \mathrm{~h}$ the rate of phenylalanine uptake into muscle was significantly increased relative to basal. If this is not simply increasing the interstitial concentration of the amino acid then it must be incorporated into tissue protein, as phenylalanine has no other metabolic fate in muscle.

Although insulin and IGF-I concentrations were also elevated in the contralateral arm at $6 \mathrm{~h}$ (Table I), it is unlikely that the increased protein synthesis was due to increases in either hormone. This follows from three observations. First, we have previously shown that increases in plasma insulin under 
euaminoacidemic conditions does not enhance human muscle protein synthesis $(10,11)$, and in the current study, the estimated rates of protein synthesis were not different in the INS + aa arm compared with the aa arm and the rises in contralateral insulin levels quite small. Second, although total IGF-I concentration in the contralateral or aa alone arm rose in the IGF+aa study, we have previously observed (using identical $(100 \mathrm{ng} / \mathrm{min}$ per $\mathrm{kg})$ or higher $(166 \mathrm{ng} / \mathrm{min}$ per $\mathrm{kg})$ intraarterial infusions of IGF-I) that this rise is not associated with a metabolic action under postabsorptive conditions (25). Finally, the aa alone arm responded very similarly in both the INS + aa and IGF+aa studies despite the apparent differences in IGF and insulin concentrations. Taken together, these observations suggest that hyperaminoacidemia per se has stimulated the synthesis of forearm protein in the aa alone arm.

These observations are in good agreement with studies of amino acid effects on whole body and muscle protein metabolism $(9,29-33,35)$. In studies of whole body amino acid flux, several groups have reported that hyperaminoacidemia alone decreased the systemic rate of appearance of leucine by 25 $50 \%(9,35)$. These results are consistent with an effect of amino acids to limit whole body proteolysis and are similar to the $\sim 30 \%$ decline in whole body phenylalanine flux seen in the current study. Unlike the marked decline observed in whole body phenylalanine flux in the present study, muscle proteolysis at $6 \mathrm{~h}$ appeared unaffected by hyperaminoacidemia. This suggests that the reduction in whole body phenylalanine flux resulted from the effects of hyperaminoacidemia on other tissues. For example, proteolysis in liver is known to be diminished by increases in the concentration of multiple different amino acids in the perfusate $(40,41)$.

In the arm receiving insulin, the net phenylalanine balance was significantly more positive than in the arm exposed to hyperaminoacidemia alone (Table IV). This further increment in phenylalanine balance appeared due to a significant suppression of protein degradation in the INS + aa arm that was not seen in the aa alone arm. In previous studies, under postabsorptive conditions increases of plasma insulin of $\sim 30 \mu \mathrm{U} / \mathrm{ml}$ suppressed skeletal muscle proteolysis and it was estimated that changes of $\sim 10-15 \mu \mathrm{U} / \mathrm{ml}$ would exert a half-maximal effect (11). Although protein degradation trended downward at $3 \mathrm{~h}$ in the aa arm contralateral to the insulin infusion, the $30 \mathrm{pmol} /$ liter rise in plasma insulin induced by the amino acid infusion in the INS + aa group was not sufficient to induce a statistically significant change in protein degradation, which is consistent with the aforementioned observations of postabsorptive subjects (11).

In the present study, therefore, insulin did not stimulate protein synthesis above the effect of amino acids alone. This observation is in agreement with human studies suggesting that hyperinsulinemia superimposed on hyperaminoacidemia does not further stimulate whole body protein synthesis (9). Considering skeletal muscle, the effects of combined hyperinsulinemia with hyperaminoacidemia have been less clear. Bennet et al. examined the effect of amino acids with or without insulin on human skeletal muscle protein turnover using sequential $3 \mathrm{~h}$ systemic infusions of amino acids followed by amino acids with insulin (29). Final insulin concentrations averaged $\sim 60 \mathrm{pmol} /$ liter and $\sim 600 \mathrm{pmol} /$ liter at the end of 3 and $6 \mathrm{~h}$, respectively. The amino acid infusion rate was increased during the insulin infusion such that the plasma phenylalanine concentration rose from 49 to $87 \mu \mathrm{M}$ with amino acids alone and further to 161 $\mu \mathrm{M}$ during the last $3 \mathrm{~h}$. While infusing only amino acids, phenylalanine balance across the leg shifted from negative to positive as seen in the forearm in the present study. Adding insulin and further increasing amino acid concentrations augmented the net uptake of phenylalanine above the amino acid alone study (29). Though interpreted to reflect an effect of insulin to increase muscle protein synthesis, several other possible explanations deserve further consideration. First, the additional increment in plasma amino acids concentration might itself have augmented tissue phenylalanine balance by stimulating protein synthesis beyond that suggested in the first $3 \mathrm{~h}$ of the study. Second, as discussed above, the additional increment in phenylalanine disappearance rate into tissue may reflect further raising of the cell and interstitium phenylalanine concentration to match that of plasma. During the last $3 \mathrm{~h}$ of the study by Bennet et al., $75 \%$ of the increment in phenylalanine balance can be accounted for by this latter process. Finally, the sequential nature of the infusions did not allow the investigators to control for an effect of time of continued amino acid infusion.

The lack of effect of insulin on protein synthesis in the current study is in accord with most previous reports of insulin's action on human skeletal muscle during euaminoacidemia (10, $11,13)$ or hypoaminoacidemia $(12,42,43)$. In contrast to these is a recent report by Biolo et al. suggesting that insulin stimulated leg muscle protein synthesis in a small number of healthy volunteers despite hypoaminoacidemia (14). In that study an increase in muscle protein synthesis was observed using both the arterial-venous difference method as applied here and in previous studies $(10-13,25,28,44)$ and by muscle biopsy. Thus, the arterio-venous method and the measurement of tracer incorporation into muscle protein yield comparable results and conclusions. It is important to note that neither the biopsy nor the arteriovenous method directly assesses the labeling of the aminoacyl-tRNA precursor pool used for protein synthesis. However, when the labeling of the aminoacyl-tRNA pool has been evaluated using either the flooding bolus method in humans $(45)$ or adult animals $(15,16)$, or by direct measurements of aminoacyl-tRNA (17), physiologic hyperinsulinemia failed to stimulate protein synthesis, in contrast to insulin's action in young, rapidly growing animals $(46,47)$.

Why Biolo et al. (14) observed an increase in muscle protein synthesis using an arteriovenous difference method when multiple others laboratories have not is not entirely clear. It is not known, for example, if the multiple biopsies from the vastus lateralis muscle may have induced local neural or more general humoral response that affected synthesis. Unfortunately, there were no control subjects not given insulin in that study nor measurements made in the contralateral, noninsulin-infused limb. In most previous human studies, insulin promoted net muscle anabolism by decreasing proteolysis $(10-13,29,44)$. Two studies, however, failed to show a significant effect of insulin on net muscle protein metabolism $(42,43)$. In each case, insulin was infused systemically (causing hypoaminoacidemia) and the balances of several amino acids shifted positively. However, though estimates of both protein synthesis and degradation trended downward these changes were not statistically significant. Though concluding that insulin did not exert an anabolic action on muscle, the authors could not exclude a type II error. Supporting this possibility is the subsequent report by Denne et al. (10), using directly comparable study design, observed significant declines in muscle proteolysis as well as slight declines in protein synthesis. Additionally, in a follow-up to an 
earlier negative study (43), Moller-Loswick et al. (13) reported positive shifts in both tyrosine and phenylalanine balance due to suppression of proteolysis during systemic insulin when hypoaminoacidemia was prevented. Interestingly, protein synthesis fell significantly in the muscle in that study.

The majority of studies of insulin action on human muscle protein metabolism, therefore, have found that insulin exerts an anabolic action via suppression of proteolysis. The lack of effect on protein synthesis had been thought to be due to the decline in plasma amino acid concentration provoked by systemic insulin infusion might limit expression of a stimulatory effect of insulin on protein synthesis. Even with local insulin infusion, which avoids confounding changes in circulating amino acids, local intracellular hypoaminoacidemia was invoked as a potentially limiting insulin's ability to stimulate protein synthesis (35). The current findings render these interpretations unlikely, particularly in light of the fact that IGF-I readily induces detectable increases in muscle protein synthesis in both the postabsorptive and hyperaminoacidemic states. There is a clear distinction, therefore, between the actions of IGF-I (and GH, [28]) to increase muscle protein synthesis and that of insulin to decrease proteolysis. In fact, given the comparable effects of IGF-I and insulin on forearm glucose uptake in the present study, IGF-I's greater positive shift in forearm phenylalanine balance suggests that it exerts a greater effect on muscle protein balance than insulin in the setting of equipotent effects on glucose uptake.

In the IGF-I-infused subjects, in response to IGF+aa, forearm phenylalanine balance was statistically different from the effects of aa alone (Fig. 2). From the tracer measurements, the added net anabolic effect of IGF-I was due to a marked increase in forearm tissue protein synthesis. This effect of IGF-I to increase protein synthesis is analogous to that previously observed under postabsorptive, euaminoacidemic conditions (25). In that dose-response study, IGF-I stimulated protein synthesis at the lowest dose used ( $30 \mathrm{ng} / \mathrm{kg}$ per $\mathrm{min}$ ) and increases up to 160 $\mathrm{ng} / \mathrm{kg}$ per min of IGF-I did not increase muscle protein synthesis further. Beyond a simple, maximal effect of IGF-I on human muscle, one possible explanation for the flat dose-response curve is that under postabsorptive conditions, amino acid availability limits the action of IGF-I to enhance protein synthesis. In the current study, by having both arms catheterized and subtracting the effect of aa alone from that observed with IGF+aa, we can gain insight into the effect of IGF-I, per se, in the setting of hyperaminoacidemia. After adjusting for the effect of aa, IGF-I increased synthesis by $52 \pm 24 \mathrm{nmol} \mathrm{PHE} / \mathrm{min}$ per 100 $\mathrm{ml}$, a change $\sim 2.5$-fold greater than that observed previously in healthy young volunteers given IGF-I alone under euaminoacidemic conditions $(P<0.05$, unpaired $t$ test $)$. Consistent with these observations in humans, Koea and colleagues observed in lambs that IGF-I ( $86 \mathrm{ng} / \mathrm{kg}$ per min) has at least an additive and in some muscles, a synergistic effect with aa on skeletal muscle protein synthesis (48).

When IGF-I was infused alone into the forearms of postabsorptive subjects, in addition to stimulating protein synthesis it suppressed proteolysis like insulin (25). In the IGF+aa forearm of the present study no consistent antiproteolytic action was observed despite prominent increases in forearm glucose uptake. Why hyperaminoacidemia would decrease the antiproteolytic action of IGF-I on muscle is not clear. Using the same experimental paradigm insulin readily decreased proteolysis, making it less likely that the failure to detect a consistent decrease in proteolysis with IGF-I was purely methodologic or by chance. Perhaps the more potent action of IGF-I to increase protein synthesis under hyperaminoacidemic conditions enhances intracellular recycling of amino acid derived from proteolysis back into newly synthesized protein, which then makes detection of a decrease in proteolysis (sampled from venous plasma) more difficult. Interestingly, analogous to the observations made here in skeletal muscle, Russell-Jones and colleagues recently demonstrated increases in whole body nonoxidative leucine disposal (NOLD) unaccompanied by any change in leucine $R_{\mathrm{a}}$ when IGF-I was co-infused with amino acids to maintain basal leucine levels (49). Despite the lack of IGF effect upon whole body leucine $R_{\mathrm{a}}$, a substantial infusion of glucose was required to maintain euglycemia at this dose of IGF-I ( $20 \mu \mathrm{g} / \mathrm{kg}$ per $\mathrm{h}$ continuously). In the same study, in contrast to IGF-I, insulin suppressed leucine flux by $19 \%$ but did not affect nonoxidative leucine flux in this model. Thus, in the whole body as well as the forearm, the insulin-like actions of IGF-I on glucose and protein appear to dissociate in the setting of exogenous amino acids. This response is clearly different from the response observed in earlier studies of whole body protein metabolism and IGF-I without amino acid replacement in which a primed, continuous infusion of IGF-I decreased whole body proteolysis and in some studies, protein synthesis $(6,7)$.

In conclusion, hyperaminoacidemia improves skeletal muscle phenylalanine balance by increasing forearm muscle protein synthesis. When combined with insulin or IGF-I, the PHE balance was more positive and therefore protein anabolism is further enhanced. In the setting of hyperaminoacidemia, these hormones exert actions similar to those observed in the postabsorptive state, i.e., insulin decreases bulk protein degradation whereas IGF-I's dominant action is to increase bulk protein synthesis.

\section{Acknowledgments}

The work reported was supported by U.S. Public Health Service grants AR01881, DK38578, and RR00847 to the University of Virginia General Clinical Research Center.

\section{References}

1. Fukagawa, N. K., K. L. Minaker, V. R. Young, and J. W. Rowe. 1986 Insulin dose-dependent reductions in plasma amino acids in man. Am. J. Physiol. 250:E13-E17.

2. Boulware, S. D., W. V. Tamborlane, L. S. Matthews, and R. S. Sherwin. 1992. Diverse effects of insulin-like growth factor I on glucose, lipid, and amino acid metabolism. Am. J. Physiol. 262:E130-E133.

3. Tessari, P., R. Trevisan, S. Inchiostro, G. Bioli, R. Nosadini, S. V. De Kreutzenberg, E. Duner, A. Tiengo, and G. Crepaldi. 1986. Dose-response curves of effects of insulin on leucine kinetics in humans. Am. J. Physiol. 251:E334E342.

4. Fukagawa, N. K., K. L. Minaker, J. W. Rowe, M. N. Goodman, D. W. Matthews, D. M. Bier, and V. R. Young. 1985. Insulin-mediated reduction of whole body protein breakdown. Dose-response effects on leucine metabolism in postabsorptive man. J. Clin. Invest. 76:2306-2311.

5. Turkalj, I. U. Keller, R. Ninnis, S. Vosmeer, and W. Stauffacher. 1992 Effect of increasing doses of recombinant human insulin-like growth factor I on glucose, lipid and leucine metabolism in man. J. Clin. Endocrinol. Metab. 75:1186-1191.

6. Elahi, D., M. McAloon-Dyke, N. K. Fukagawa, A. L. Sclater, G. A. Wong, R. P. Shannon, K. L. Minaker, J. M. Miles, A. H. Rubenstein, C. J. Vandepol, et al. 1993. Effects of recombinant human IGF-I on glucose and leucine kinetics in man. Am. J. Physiol. 265:E831-E838.

7. Laager, R., R. Ninnis, and U. Keller. 1993. Comparison of the effects of recombinant human insulin-like growth factor-I and insulin on glucose and leucine kinetics in humans. J. Clin. Invest. 92:1903-1909.

8. Flakoll, P. J., M. Kulaylat, M. Frexes-Steed, H. Hourani, L. L. Brown, J. O. 
Hill, and N. N. Abumrad. 1989. Amino acids augment insulin's suppression of whole body proteolysis. Am. J. Physiol. 257:E839-E847.

9. Castellino, P., L. Luzi, D. C. Simonson, M. Haymond, and R. A. DeFronzo 1987. Effect of insulin and plasma amino acid concentrations on leucine metabolism in man. J. Clin. Invest. 80:1784-1793.

10. Gelfand, R. A., and E. J. Barrett. 1987. Effect of physiologic hyperinsulinemia on skeletal muscle protein synthesis and breakdown in man. J. Clin Invest. 80:1-6.

11. Louard, R. J., D. A. Fryburg, R. A. Gelfand, and E. J. Barrett. 1992 Insulin sensitivity of protein and glucose metabolism in human forearm skeletal muscle. J. Clin. Invest. 90:2348-2354.

12. Denne, S. C., E. A. Liechty, Y. M. Liu, G. Brechtel, and A. D. Baron 1991. Proteolysis in skeletal muscle and whole body in response to euglycemic hyperinsulinemia in normal adults. Am. J. Physiol. 261:E809-E814.

13. Moller-Loswick, A. C., H. Zachrisson, A. Hyltander, U. Korner, D. E. Matthews, and K. Lundholm. 1994. Insulin selectively attenuates breakdown of nonmyofibrillar proteins in peripheral tissues of normal men. Am. J. Physiol. 266:E645-E652.

14. Biolo, G., R. Y. D. Fleming, and R. R. Wolfe. 1995. Physiologic hyperinsulinemia stimulates protein synthesis and enhances transport of seclected amino acids in human skeletal muscle. J. Clin. Invest. 95:811-819.

15. Baillie, A. G. S., and P. J. Garlick. 1992. Attenuated responses of muscle protein synthesis to fasting and insulin in adult female rats. Am. J. Physiol 262:E1-E5.

16. McNulty, P. H., L. H. Young, and E. J. Barrett. 1993. Response of rat heart and skeletal muscle protein in vivo to insulin and amino acid infusion. Am. J. Physiol. 264:E958-E965.

17. Young, L. H., W. Stirewalt, P. H. McNulty, J. H. Revkin, and E. J. Barrett. 1994. Effect of insulin on rat heart and skeletal muscle phenylalanyltRNA labeling and protein synthesis in vivo. Am. J. Physiol. 267:E337-E342.

18. Tauveron, I., D. Larbaud, C. Champredon, E. Debras, S. Tesseraud, G. Bayle, Y. Bonnet, P. Thieblot, and J. Grizard. 1994. Effect of hyperinsulinemia and hyperaminoacidemia on muscle and liver protein synthesis in lactating goats. Am. J. Physiol. 267:E877-E855.

19. Jefferson, L. S., D. E. Rannels, B. L. Munger, and H. E. Morgan. 1974 Insulin in the regulation of protein turnover in heart and skeletal muscle. Fed. Proc. 33:1098-1104.

20. Jefferson, L. S., 1980. Role of insulin in the regulation of protein synthesis Diabetes. 29:487-496.

21. Flaim, K. E., P. J. Kochel, Y. Kira, K. Kobayashi, E. T. Fossel, L. S Jefferson, and H. E. Morgan. 1983. Insulin effects on protein synthesis are independent of glucose and energy metabolism. Am. J. Physiol. 245:C133-C143.

22. Harper, J. M. M., J. B. Soar, and P. J. Buttery. 1987. Changes in protein metabolism of ovine primary cultures on treatment with growth hormone, insulin, insulin-like growth factor I or epidermal growth factor. J. Endocrinol. 112:8796.

23. Monier, S., A. Le Cam, and Y. Le Marchand-Brustel. 1983. Insulin and insulin-like growth factor I. Effects on protein synthesis in isolated muscles from lean and goldthioglucose-obese mice. Diabetes. 32:392-397.

24. Fuller, S. J., J. R. Mynett, and P. H. Sugden. 1992. Stimulation of cardiac protein synthesis by insulin-like growth factors. Biochem. J. 282:85-90.

25. Fryburg, D. A. 1994. Insulin-like growth factor I exerts growth hormoneand insulin-like actions on human muscle protein metabolism. Am. J. Physio 267:E331-E336.

26. Tomas, F. M., S. E. Knowles, P. C. Owens, L. C. Read, C. S. Chandler S. E. Gargosky, and F. J. Ballard. 1991. Effects of full-length and truncated insulin-like growth factor-I on nitrogen balance and muscle protein metabolism in nitrogen-restricted rats. J. Endocrinol. 128:97-105.

27. Douglas, R. G., P. D. Gluckman, K. Ball, and J. H. F. Shaw. 1991. The effects of infusion of insulin-like growth factor (IGF)-I, IGF-II, and insulin on glucose and protein metabolism in fasted lambs. J. Clin. Invest. 88:614-622.

28. Fryburg, D. A., R. A. Gelfand, and E. J. Barrett. 1991. Growth hormone acutely stimulates forearm muscle protein synthesis in normal humans. Am. J. Physiol. 260:E499-E504.

29. Bennet, W. M., A. A. Connacher, C. M. Scrimgeour, R. T. Jung, and
M. J. Rennie. 1990. Euglycemic hyperinsulinemia augments amino acid uptake by leg tissues during hyperaminoacidemia. Am. J. Physiol. 259:E185-E194.

30. Nair, K. S., R. G. Schwartz, and S. Welle. 1992. Leucine as a regulator of whole body and skeletal muscle protein metabolism in humans. Am. J. Physiol. 263:E928-E934.

31. Pacy, P. J., J. S. Garrow, G. C. Ford, H. Merritt, and D. Halliday. 1988. Influence of amino acid administration on whole-body leucine kinetics and resting metabolic rate in postabsorptive normal subjects. Clin. Sci. 75:225-231.

32. Frexes-Steed, M., D. B. Lacy, J. Collins, and N. N. Abumrad. 1992. Role of leucine and other amino acids in regulating protein metabolism in vivo. Am. J. Physiol. 262:E925-E935.

33. Gelfand, R. A., M. G. Glickman, P. Castellino, R. J. Louard, and R. A. DeFronzo. 1988. Measurement of $\mathrm{L}-\left[1-{ }^{14} \mathrm{C}\right]$ leucine kinetics in splanchnic and leg tissues in humans. Effects of amino acid infusion. Diabetes. 37:1365-1372.

34. Fukagawa, N. K., K. L. Minaker, V. R. Young, D. E. Matthews, D. M.

Bier, and J. W. Rowe. 1989. Leucine metabolism in ageing humans, effect of insulin and substrate availability. Am. J. Physiol. 256:E288-E294.

35. Bennet, W. M., A. A. Connacher, C. M. Scrimgeour, and M. J. Rennie. 1990. The effect of amino-acid infusion on leg protein turnover assessed by $\mathrm{L}$ [15N]phenylalanine and L- $\left[1-{ }^{13} \mathrm{C}\right]$ leucine exchange. Eur. J. Clin. Invest. 20:3746.

36. Barrett, E. J., J. H. Revkin, L. H. Young, B. L. Zaret, R. Jacob, and R. A. Gelfand. 1987. An isotopic method for in vivo measurement of muscle protein synthesis and degradation. Biochem. J. 245:223-228.

37. Barrett, E. J., and R. A. Gelfand. 1989. The in vivo study of cardiac and skeletal muscle protein turnover. Diabetes Metab. Rev. 5:133-148.

38. Watt, P., Y. Lindsay, C. Scrimgeour, P. Chien, J. Gibson, D. Taylor, and M. J. Rennie. 1991. Isolation of aminoacyl-tRNA and its labeling with stableisotope tracers, use in studies of human tissue protein synthesis. Proc. Natl. Acad. Sci. USA. 88:5892-5896.

39. Morgan, H. E., D. C. N. Earl, A. Broadus, E. B. Wolpert, K. E. Giger, and L. S. Jefferson. 1971. Regulation of protein synthesis in heart muscle. I. Effect of amino acid levels on protein synthesis. J. Biol. Chem. 246:2152-2162.

40. Mortimore, G. E., A. R. Poso, and B. R. Lardeux. 1989. Mechanism and regulation of protein degradation in liver. Diabetes Metab. Rev. 5:48-70.

41. Venerando, R., G. Miotto, M. Kadowaki, N. Siliprandl, and G. E. Mortimore. 1994. Multiphasic control of proteolysis by leucine and alanine in the isolated rat hepatocyte. Am. J. Physiol. 266:C455-C461.

42. Tessari, P., S. Inchiostro, G. Biolo, E. Vincenti, and L. Sabadin. 1991. Effects of acute systemic hyperinsulinemia on forearm muscle proteolysis in healthy man. J. Clin. Invest. 88:27-33.

43. Arfvidsson, B., H. Zachrisson, A.-C. Moller-Loswick, A. Hyltander, R. Sandstrom, and K. Lundholm. 1991. Effect of systemic hyperinsulinemia on amino acid flux across human legs in the postabsorptive state. Am. J. Physiol. 260:E46-E52.

44. Heslin, M. J., E. Newman, R. F. Wolf, P. W. T. Pisters, and M. F. Brennan. 1992. Effect of hyperinsulinemia on whole body and skeletal muscle leucine carbon kinetics in humans. Am. J. Physiol. 262:E911-E918.

45. McNurlan, M. A., P. Essen, A. Thorell, A. G. Calder, S. E. Anderson, O. Ljungquist, A. Sandgren, I. Grant, I. Thader, P. E. Ballmer, et al. 1994. Response of protein syunthesis in human skeletal muscle to insulin: an investigation with L- $\left[{ }^{2} \mathrm{H}_{5}\right]$ phenylalanine. Am. J. Physiol. 267:E102-E108.

46. Garlick, P. J., M. Fern, and V. R. Preedy. 1983. The effect of insulin infusion and food intake on muscle protein synthesis in postabsorptive rats. Biochem. J. 210:669-676.

47. Garlick, P. J., and I. Grant. 1988. Amino acid infusion increases the sensitivity of muscle protein synthesis in vivo to insulin. Biochem. J. 254:579584.

48. Koea, J. B., R. G. Douglas, B. H. Breier, J. H. F. Shaw, and P. D. Gluckman. 1992. Synergistic effect of insulin-like growth factor-I administration on the protein-sparing effects of total parenteral nutrition in fasted lambs. Endocrinology. 131:643-648.

49. Russell-Jones, D. L., A. M. Umpleby, T. R. Hennessy, S. B. Bowes, F. Shojaee-Moradie, K. D. Hopkins, N. C. Jackson, J. M. Kelly, R. H. Jones, and P. H. Sonksen. 1994. Use of a leucine clamp to demonstrate that IGF-I actively stimulates protein synthesis in normal humans. Am. J. Physiol. 267:E591-E598. 